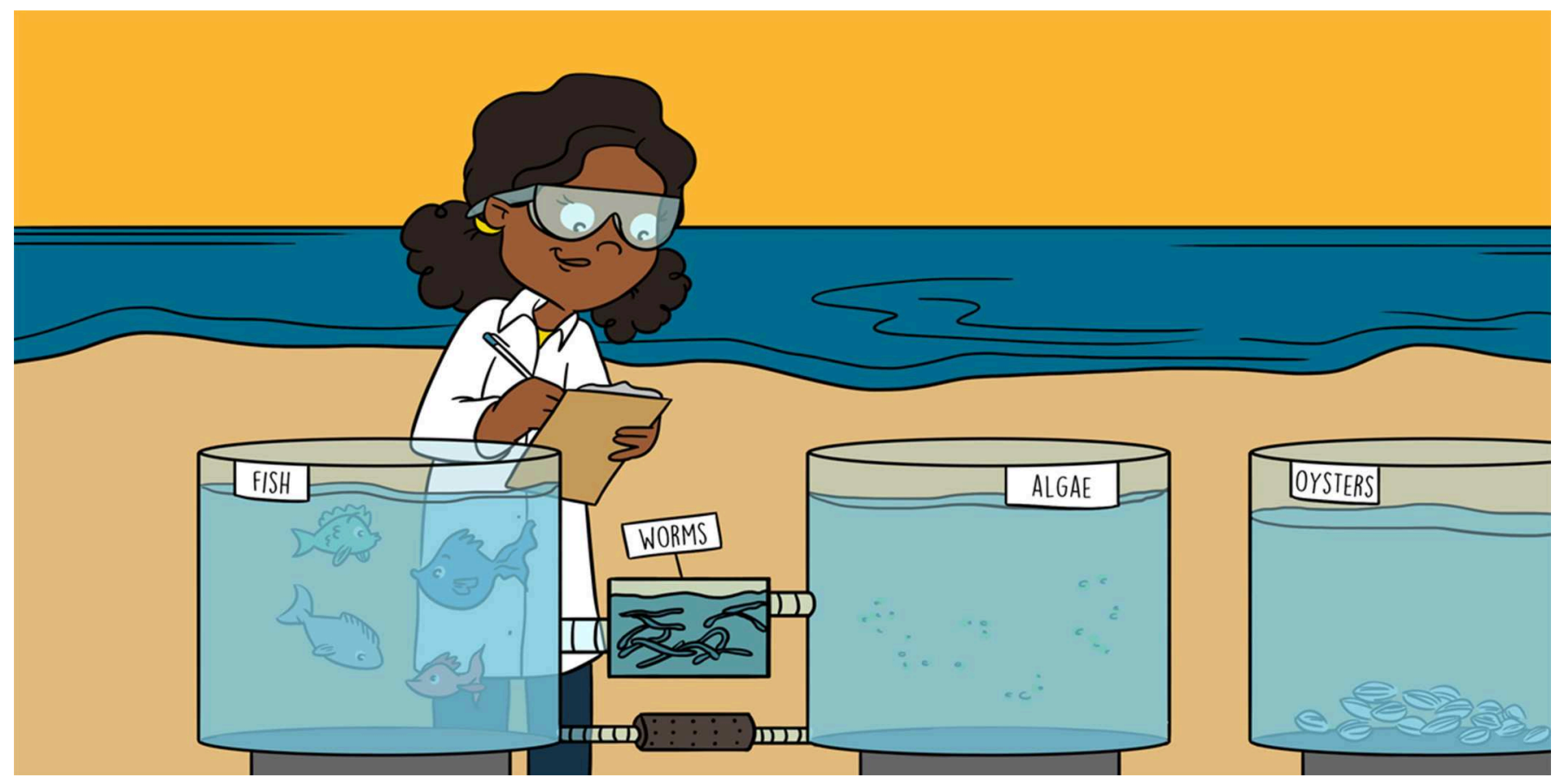

\title{
FISH, ALGAE, AND OYSTERS: THE WINNING TRIO IN AQUACULTURE
}

\section{Emmanuelle Roque D'Orbcastel ${ }^{1^{*}}$, Elyse Boudin ${ }^{2}$, Meng $\mathrm{Li}^{3,4}$, Frédérique Carcaillet ${ }^{2}$ and Eric Fouilland ${ }^{1}$}

${ }^{1}$ MARBEC, University of Montpellier, IRD, Ifremer, CNRS, Sète, France

${ }^{2}$ MARBEC, University of Montpellier, IRD, Ifremer, CNRS, Montpellier, France

${ }^{3}$ Fisheries College, Ocean University of China, Qingdao, China

${ }^{4}$ MARBEC, University of Montpellier, IRD, Ifremer, CNRS, Palavas-les-Flots, France

\section{YOUNG REVIEWERS:}

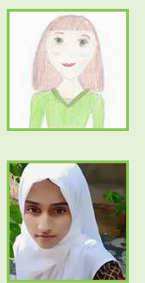

ANNA-MARIE

AGE: 15

SAMEEN

AGE: 14
Most older methods of fish farming, or aquaculture, have focused on growing only a single species of sea life, for example, salmon. Modern aquaculture systems involve the cultivation of two or more species together, based on what happens normally in the food chain, so that one species can provide a source of food for another species in the farm. This article describes the results of an experiment combining fish culture with algae culture and oyster culture. We show that algae can grow using fish waste, and oysters can eat algae to produce good-quality, healthy food, which reduces the pollution generated by aquaculture.

\section{AQUACULTURE}

Humans eat a huge number of animals and plants from the sea. Sea meals can include fish, shellfish, and algae. Usually purchased either 
Figure 1

This comic shows the natural food chain, with a combination of complementary species: carnivorous and omnivorous fishes, sea cucumber as a detritivorous species, algae that consume nutrients present in water, and filter feeders (such as mussels) that feed on small organic particles. Scientists took inspiration from the food chain to create integrated multi-trophic aquaculture systems, in which species feed on each other according to their mode of feeding. From Frederic Neidhardt (humorist).

\section{AQUACULTURE}

Comes from the Latin, "aqua," for water and "culture," which means to grow, and therefore means something "grown in water."

\section{FOOD CHAIN}

The feeding relationships between organisms; plants are at the bottom of the food chain and are called producers. Organisms that eat plants are called consumers. A food chain shows how each living thing gets food, and how nutrients and energy are passed from creature to creature.

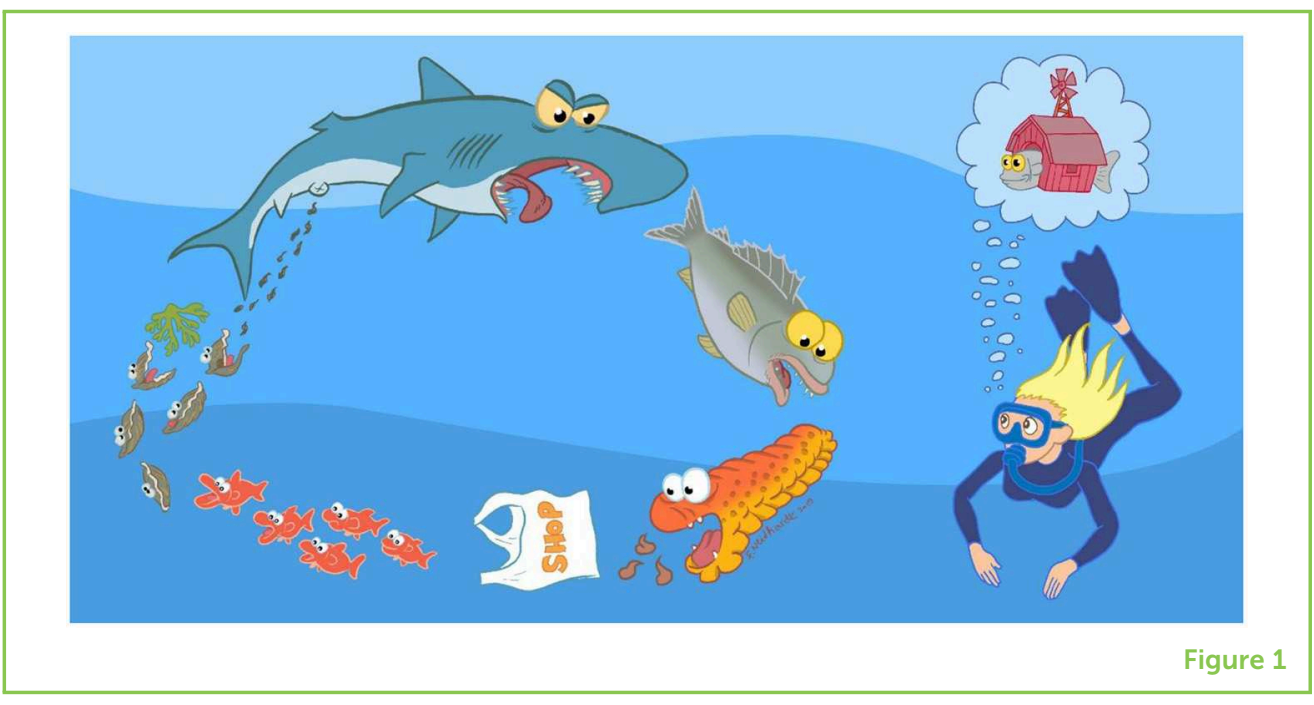

fresh or frozen from the supermarket, these seafood products have either been harvested from their natural environment or raised by humans in farms consisting of tanks connected to the sea or cages in the sea. The farming of sea animals and plants by humans is called aquaculture.

The word aquaculture comes from the Latin, "aqua," for water and "culture," which means to grow, and therefore means "grown in water." Aquaculture helps us to avoid depletion of sea resources by over-fishing, and it also helps us to produce enough food to feed the growing number of humans on earth. Fish farmers know the precise quality of the water used, and the quantity of animals they raise to sell. Fish farmers can also choose fish species according to a region's climate and the type of seafood commonly eaten by the people living in that region.

There are several methods of aquaculture. Generally, sea farmers specialize in what is called single-species culture, which means farming one thing, like fish, seaweed, or shellfish (oysters or mussels). This type of farming is what we will refer to in this article as conventional aquaculture. Alternatively, some sea farmers grow different species together, at the same time!

There are several reasons why sea farmers sometimes grow different species together. Species have different modes of feeding: some only feed on other animals (carnivores), some feed on other animals and algae (omnivores), and some only feed on algae (herbivores). In the natural ecosystem of the sea, algae feed on small molecules in the water; species, such as oysters feed on algae; species, such as herbivorous fish feed on algae and sea plants; while carnivorous fish feed on small animals (Figure 1); and finally, some starfish and worms, called detritivores, feed on the feces of other animals! These different modes of feeding make up the food chain, and humans 
Figure 2

Diagram of the connections between the tanks in an experimental integrated multi-trophic aquaculture system. Sea water comes into the fish tank. Waste from the fish tank is eaten by sea worms/cucumbers or passes through filters, and the remaining wastewater contains nitrogen (N) and phosphorus (P) that are consumed by microalgae. The microalgae are eaten by oysters, and then clean water can then be safely returned to the sea. Illustration from E. Boudin.

IMTA OR

INTEGRATED

MULTI-TROPHIC AQUACULTURE

Way of aquaculture with multiple species grown together.

\section{MICROALGAE}

Microscopic algae that use sunlight, water, minerals, $(N, P)$ and $\mathrm{CO}_{2}$ for their growth.

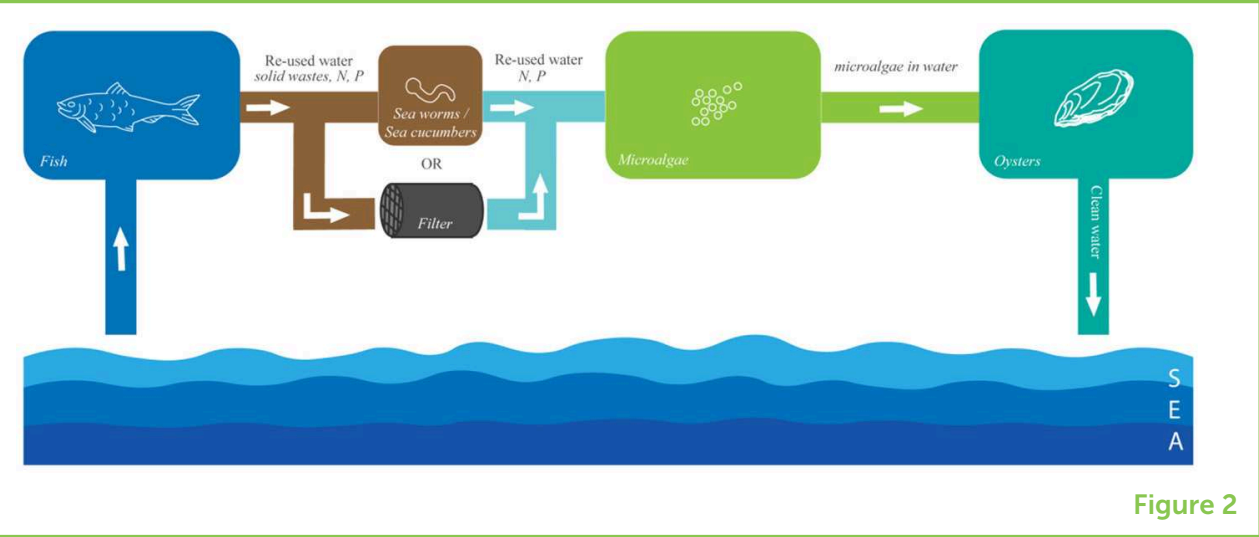

can use the food chain to design environmentally friendly sea farms. For example, algae can be used to purify the water where fish are farmed. This allows the water to be reused and then dumped into the sea without polluting the environment. If sea farmers cultivate certain types of algae, they can feed it to oysters. In this way, sea farmers replicate the food chain in their farms. This way of aquaculture, where multiple species are grown together, is called integrated multi-trophic aquaculture (IMTA).

\section{WHAT IS SO GREAT ABOUT INTEGRATED MULTI-TROPHIC AQUACULTURE?}

IMTA gives farmers new ways to produce food for humans or animals. In addition to fish, farmers can grow algae (large ones called macroalgae or small ones called microalgae), oysters or mussels, worms, or sea cucumbers. Microalgae can be used as ingredients for human food, animal feed, cosmetics and even biofuel. Once the algae have cleaned the fish's water, sea farmers no longer need to use expensive water treatment. This saves them a lot of money.

Let us look at an IMTA farm that was studied by French researchers (Figure 2). Each species is raised in a separate tank, where its growth is carefully controlled. Solid waste from fish, such as feces, can be removed by passing the water through a filter or by directing the water into a tank where worms feed on the waste particles. The particle-free water is then discharged into a tank full of microalgae. The water still contains very small molecules that are invisible to the naked eye-just like when sugar is mixed in water-but these molecules can be used as nutrients by the microalgae. Once the microalgae clean the water, it can then be reused in fish tanks or discharged into the sea without causing pollution. The farmed microalgae are ultimately used as food for oysters.

However, in order to have a fully functioning sea farm, there must be enough worms and microalgae to clean the water in the tanks and 
Figure 3

The experimental set-up of the IMTA. The fish tanks $(\mathrm{A})$ are connected to the microalgae tanks (B), which feed the oyster tanks (C) (source: E. Roque D'Orbcastel, UMR MARBEC).
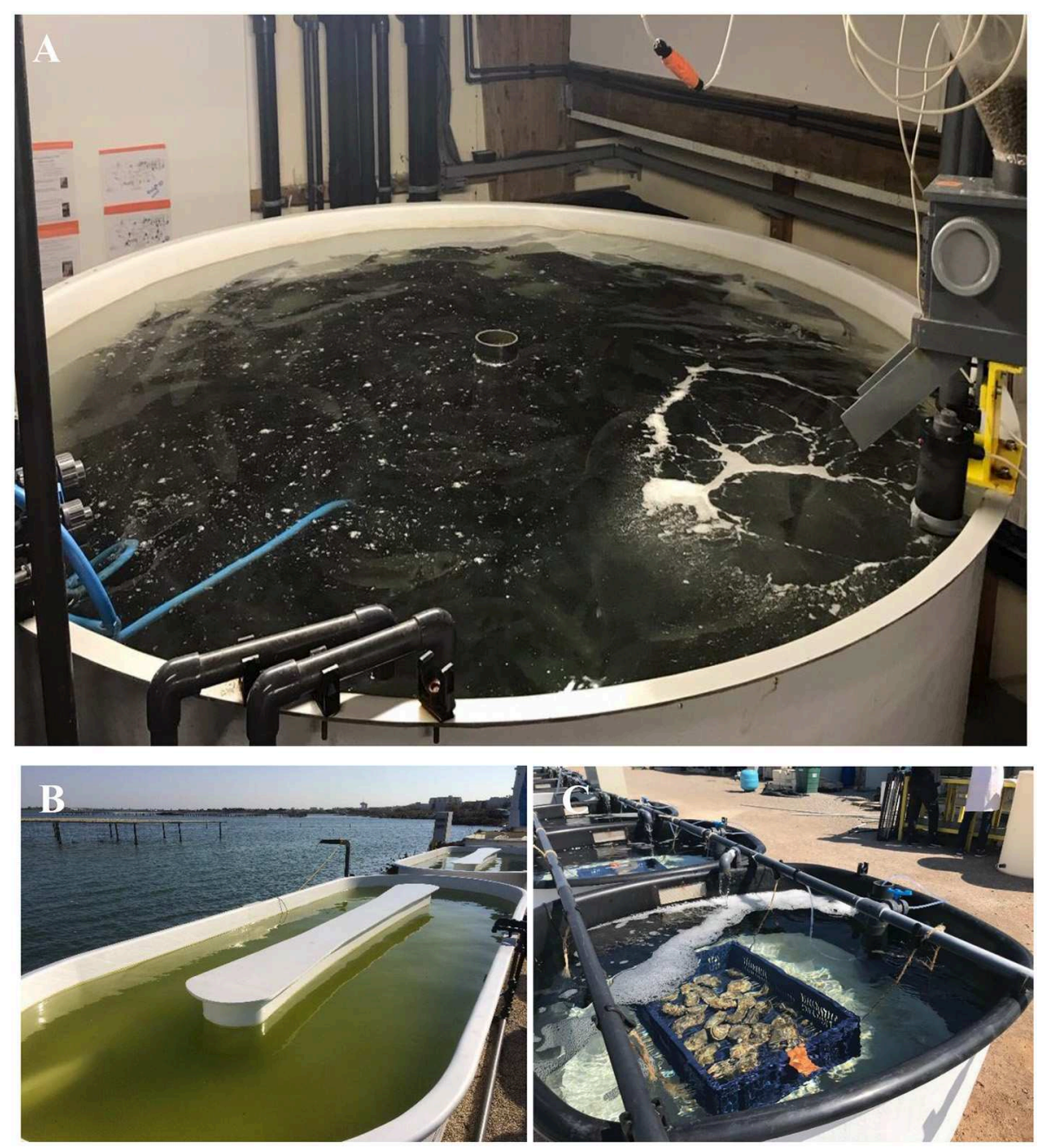

Figure 3

enough microalgae to feed the oysters. It is often difficult to maintain the perfect balance between the different tanks, because they are easily affected by climate factors like rain and temperature, as well as by the presence of undesirable species, like parasites or organisms that eat algae. This is why researchers are working with fish farmers to find the best ways to connect the tanks and to better control the growth of the species being farmed.

\section{TEAMWORK: RESEARCHERS AND FISH FARMERS}

First, the researchers tested the microalgae's ability to clean the water from the fish tanks. Second, they tested the microalgae's suitability as food for oysters and whether the oysters grown this way were good enough for human consumption.

The researchers connected three different tanks: a fish culture tank, a microalgae culture tank, and an oyster culture tank (Figure 3). To be sure of their results and to have enough data, researchers always work 
with three replicates of each experiment, so, in total, there were three fish tanks, three microalgae tanks and three oyster tanks. This means that if the animals died in one of the tanks, researchers could still get results from the other two. Researchers placed filters between the fish tanks and microalgae tanks, to remove the solid waste produced by the fish. This experiment lasted 2 months, and various measurements were taken.

To observe the microalgae's water-cleaning ability, researchers measured the water quality both in the fish tank and in the microalgae tank. The fish waste was mainly composed of nitrogen (N) and phosphorus (P). The researchers found that there was almost no waste left in the water when it exited the microalgae tank, because the microalgae had consumed most of it. The researchers concluded that microalgae are very efficient at removing the $\mathrm{N}$ and $\mathrm{P}$ waste produced by the fish.

To test whether the microalgae are suitable food for oysters, the researchers measured the size of the oysters at the beginning and at the end of the 2-months experiment. Normally, the more oysters eat, the bigger they are. But surprisingly, in this experiment, the oyster growth was poor, and some oysters did not grow at all. Two hypotheses could explain the poor growth of the oysters. First, it was possible that the type of microalgae used did not meet the oyster's nutritional requirements. A second possibility is that there was not enough algae in the oyster tanks to feed all the oysters.

To test the two possible hypotheses, further investigations were conducted to determine whether the IMTA-produced algae were a good food source for the oysters. Results showed that the oysters could grow from eating IMTA-algae. This means that the second hypothesis was probably the right one: there were not enough algae in the water to feed all the oysters during the 2-months experiment. This was because the water in the oyster tank was not sufficiently mixed, preventing the algae from reaching the oysters. The next step will be for the researchers to carry out the experiment again after improving the water circulation in the oyster tanks.

In conclusion, integrated multi-trophic aquaculture is a research topic that requires researchers and fish farmers to work together to improve aquaculture farming. By recreating a simple food chain, IMTA makes use of one of the fundamental principles of nature: all species are useful and are inter-linked as either prey or predator. When imitating nature, humans can develop methods that are better for the farmed species and for the environment. 


\section{ORIGINAL SOURCE ARTICLE}

Li, M., Callier, M. D., Blancheton, J.-P., Galès, A., Nahon, S., Triplet, S., et al. 2019. Bioremediation of fishpond effluent and production of microalgae for an oyster farm in an innovative recirculating integrated multi-trophic aquaculture system. Aquaculture 504:314-25. doi: 10.1016/j.aquaculture.2019.02.013

SUBMITTED: 03 July 2019; ACCEPTED: 13 November 2019;

PUBLISHED ONLINE: 28 November 2019.

EDITED BY: Didone Frigerio, University of Vienna, Austria

CITATION: Roque D'Orbcastel E, Boudin E, Li M, Carcaillet F and Fouilland E (2019) Fish, Algae, and Oysters: The Winning Trio in Aquaculture. Front. Young Minds 7:131. doi: 10.3389/frym.2019.00131

CONFLICT OF INTEREST: The authors declare that the research was conducted in the absence of any commercial or financial relationships that could be construed as a potential conflict of interest.

COPYRIGHT @ 2019 Roque D'Orbcastel, Boudin, Li, Carcaillet and Fouilland. This is an open-access article distributed under the terms of the Creative Commons Attribution License (CC BY). The use, distribution or reproduction in other forums is permitted, provided the original author(s) and the copyright owner(s) are credited and that the original publication in this journal is cited, in accordance with accepted academic practice. No use, distribution or reproduction is permitted which does not comply with these terms.

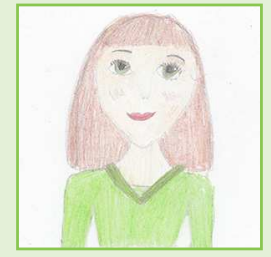

\section{YOUNG REVIEWERS}

\section{ANNA-MARIE, AGE: 15}

My favorite subject is biology, I like bionics. In future I would like to work on new materials, new substances. I am curious about the mysteries of the universe, there is so much to discover.

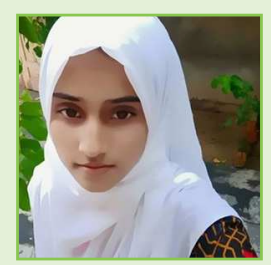

\section{SAMEEN, AGE: 14}

Hello, I am Sameen from Mandi Bahauddin (M.B.Din). My school is very competitive especially in science subjects but I like biology. I like to know about natural processes especially in aquatic species. I love to read newspaper, history books and learn new languages. Besides, I wish to participate in environmental clubs and field trips. I want to study the ecosystems and biology when I grow up. 


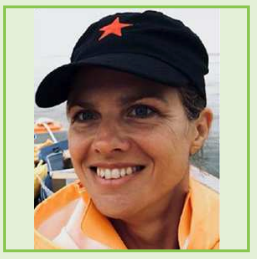

\section{AUTHORS}

\section{EMMANUELLE ROQUE D'ORBCASTEL}

Emmanuelle Roque D'Orbcastel is a researcher in Marine Biology, at the Ifremer Institute, attached to the MARBEC (Marine Biodiversity, Exploitation, and Conservation) Unit (south of France). The unit's objective is the study of marine biodiversity, and the human race's use of species, in different ecosystems. More specifically, Emmanuelle works on aquaculture ecosystems, studying interactions between animals (i.e., fish) and their environment, especially the animal welfare. She is also interested in working with fish farmers to find ways of reducing environmental impacts, by treating or otherwise using waste from fish farms. *emmanuelle.roque@ifremer.fr
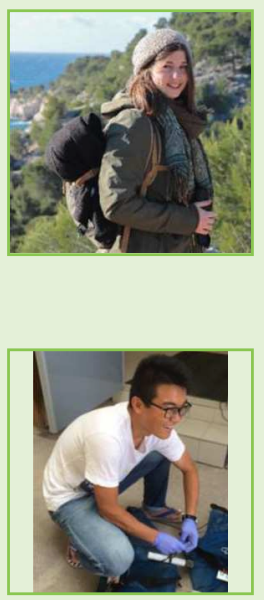

\section{ELYSE BOUDIN}

Elyse Boudin is finishing a master's degree in Ecology Engineering at the University of Montpellier. This work was a part of her master's internship at the Marine Biodiversity Exploitation and Conservation laboratory (MARBEC). She wants to work education, teaching environmental concepts and sustainable development, to create a bridge between researchers and young people.

\section{MENG LI}

Meng Li has is a post-doc at the School of Environment, Tsinghua University. He got his Ph.D. in agriculture from Ocean University of China in July, 2018. During his Ph.D. work, he had a 12-months internship at IFREMER in France, participating in the European research project "IMTA EFFECT (COFASP 2016-2019) - Integrated Multi Trophic Aquaculture for Efficiency and Environmental Conservation." Li's main research interests are aquaculture wastewater treatment (for example with constructed wetlands) and the development of integrated multi-trophic aquaculture.

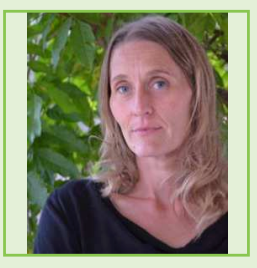

\section{FRÉDÉRIQUE CARCAILLET}

Dr. Frédérique Carcaillet is senior lecturer in Aquatic Ecology at the University of Montpellier in France, where she mainly teaches ecology and environmental science communication. Her research includes ecosystem function, science communication, and environmental education. She runs science animation film workshops to teach students how to communicate science to the general public. https://www.youtube.com/channel/UCdMXIvXqFZxiSFtsnFUQiZg/videos

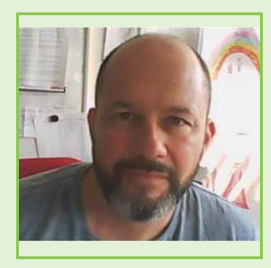

\section{ERIC FOUILLAND}

Eric Fouilland is a researcher at the National Centre of Scientific Research in France. His research focuses on interactions between microalgae and bacteria in different marine environments (Arctic, Antarctic, tropical, and temperate waters). His work has shown that strong interactions with bacteria may occur when microalgae are growing rapidly. This observation has many applications in the field of water depollution, biofuels, and aquaculture, by using microalgae in association with specific bacteria to boost algal growth. Aside from his research, he enjoys spending time with his five kids and drinking red wine with good friends from all around the world. 